\title{
Conduction velocity in the proximal segments of a motor nerve in the Guillain-Barré syndrome
}

\author{
D A VID K ING A N D PETER ASHBY
}

\author{
From the EMG Department, Toronto Western Hospital, Toronto, Ontario, Canada
}

SYNOPSIS Conduction velocity from spinal cord to axilla (estimated using the F wave) has $\varnothing$ been compared with conduction velocity from axilla to wrist (measured in the conventionalœ manner) in the motor fibres of the ulnar nerve in 17 control subjects and in 11 patients with $\vec{\circ}$ the Guillain-Barre syndrome (GBS). In the patients with GBS the conduction velocity was, in general, reduced to a similar extent in both the proximal and the distal portions of the motor ${ }_{\mathcal{O}}^{\bar{\omega}}$ fibres, suggesting that the disease process is usually diffuse. In two patients, however, the conduction velocity in the proximal segment was disproportionally reduced and in one of these the conduction velocity in the distal segment was normal. It is concluded that the estimation of conduction velocity in the proximal segments of motor nerves may be of valutio in the assessment of patients with GBS.

Patients with the Guillain-Barré syndrome (GBS) commonly develop a reduction in motor nerve fibre conduction velocity which helps to differentiate the condition from other types of neuromuscular disease (Peterman et al., 1959; Cerra and Johnson, 1961; Lambert and Mulder, 1964; Isch et al., 1967; Kaeser, 1970; McQuillen, 1971; Eisen and Humphreys, 1974). The reduced conduction velocity can be attributed to an increase in the internodal conduction time resulting from segmental demyelination (Rasminsky and Sears, 1973).

Conduction velocity is usually measured in the most accessible distal segment of motor nerves. The slowing of nerve conduction velocity in this segment is usually uniform but may be patchy (Bigot and Goulon, 1970; Kaeser, 1970), most marked distally (Isch et al., 1967), or most marked at potential sites of nerve compression (Lambert and Mulder, 1964). Although sometimes present within a few days of the onset of symptoms, the characteristic reduction in conduction velocity may not be ap-

Address for correspondence: Dr. P. Ashby, 25 Leonard Avenue Toronto M5T 2R2, Ontario, Canada.

(Accepted 20 January 1976.) parent until two to three weeks after the onset of the syndrome (Peterman et al., 1959; Hun phreys, 1964; Kaeser, 1970; Eisen and Hum phreys, 1974).

In a proportion (10-20\%) of patients with otherwise typical GBS it is not possible to demonstrate slowing of conduction in the distal segments of motor nerves even at the peak of the neurological deficit (Lambert and Mulder, 1964; McQuillen, 1971; De Jesus, 1974; Eisen and Humphreys, 1974). There are several possible explanations for this:

(1) the disease process could be so mild that the conduction velocity of the fastest motor fibres is not depressed below the normal range; (2) the demyelination could involve predominantly the roots or proximal portions of the spinal nerves where conduction can not be measured using conventional techniques (Kaeser, 1970; Eisen and Humphreys, 1974); (3) the weakness could result from conduction block (Kaeser, 1970) or axonal disruption (Oppenheimer and Spalding, 1973). The O measurement of conduction velocity in the proximal portions of motor nerves would $\underset{\omega}{ }$ clearly help to distinguish between these possibilities. 
Kimura (1974) has devised a method of estimating conduction velocity in motor nerve fibres from the spinal cord to the proximal part of the limb using the $F$ wave. In the present study, the conduction velocities from the spinal cord to axilla (estimated with this technique) and axilla to wrist (estimated in the usual way) in the motor fibres of the ulnar nerve are compared in normal subjects and in a group of patients with GBS of varying degrees of severity. It is concluded that the technique is of value in the assessment of patients with GBS. Kimura and Butzer (1975) have recently published the findings of a similar study in patients with mild GBS.

\section{METHODS}

Studies were carried out on 17 control subjects and 11 patients with GBS. The control subjects were either normal volunteers (nine) or patients (eight) referred for electrophysiological examination for conditions that were unlikely to affect conduction in the upper limbs.

The patients with GBS were those who had attended the electromyographic laboratory in the previous four years. Some patients were examined during the acute phase of the disease and others recalled for examination during convalescence. The diagnosis of GBS was accepted if the patients had had the typical onset of progressive weakness, with areflexia, attributable to a symmetrical polyneuropathy, accompanied by a raised CSF protein. The patient's clinical condition at the time of the electromyographic examination was graded as 'normal', 'mild' (definite neurological deficit but not hospitalized), 'moderate' (hospitalized but able to sit or stand), and 'severe' (hospitalized and unable to sit or stand or requiring ventilation).

Proximal conduction was determined by the method devised by Kimura (1974). Electrical stimuli generated by a Grass S 88 stimulator were delivered to the ulnar nerve at the wrist and/or axilla through gold plated bipolar surface electrodes $0.5 \mathrm{~cm}$ in diameter, $3 \mathrm{~cm}$ apart. The compound action potential of the abductor digiti minimi was recorded with spring clip electrodes (C. F. Palmer (London) Ltd.), amplified using a Tektronix 2A61 differential amplifier with filter settings $0.6 \mathrm{~Hz}$ and $10 \mathrm{kHz}$, and displayed on a Tektronix 561A and a Tektronix 564 storage oscilloscope. The traces were photographed using a Tektronix C 12 Polaroid camera.

A supramaximal stimulus was delivered to the ulnar nerve at the wrist and at the axilla and conduction velocity in the fastest motor fibres calculated in the conventional manner. Supramaximal stimuli were then delivered to the ulnar nerve at the wrist and at the axilla simultaneously, allowing the compound action potential of the abductor digiti minimi generated by the stimulus at the wrist, and the $F$ wave generated by the stimulus at the axilla to be visualized. When two stimuli are delivered simultaneously to the ulnar nerve in this way the orthodromic volley resulting from the axillary stimulus cannot evoke a muscle action potential as it collides with the antidromic volley generated at the wrist. After checking that the orthodromic volley from the proximal site of stimulation had been successfully blocked, the amplification was increased in order to examine the $\mathrm{F}$ waves in more detail. The latency of the earliest proximally evoked $\mathrm{F}$ wave was measured from its onset. The latency axilla-cord-axilla was determined by subtracting the distal latency of the compound action potential produced by the isolated axillary stimulus and by subtracting a further, arbitrary, $1.0 \mathrm{~ms}$ to allow for the reactivation of the anterior horn cells. The distance from the proximal point of stimulation to the vertebra prominens was measured in the manner described by Kimura (1974).

Comparisons of proximal and distal conduction velocities in the normal and patient populations were made using Student's $t$ test and the correlation coefficient. Probabilities of less than 0.5 (two tailed) were considered significant.

\section{RESULTS}

The technique was found to be relatively simple and studies could usually be completed within 10 minutes. In normal subjects, the proximally evoked muscle compound action potential could be readily blocked (Fig. 1), and several $F$ waves each having a consistent latency obtained (Fig. 2). The estimates of the conduction velocity measured using the $F$ wave conformed closely to estimates of conduction from Erb's point to the axilla obtained in the conventional manner in subjects in whom this could be carried out. In the patients with GBS, who often had dispersed and irregular compound muscle action potentials, the $F$ waves could generally be recognized by the characteristic variability of their occurrence and their constant latency (Fig. 3). 


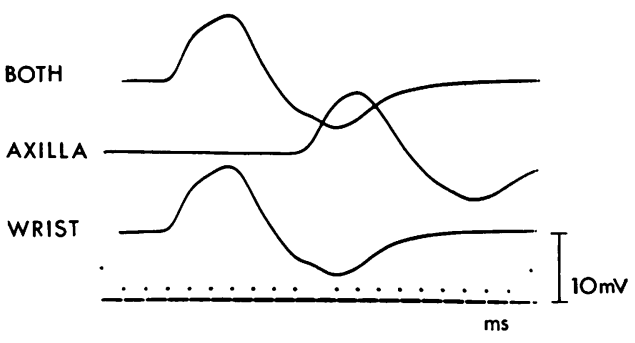

FIG. 1 Extinction of the orthodromic $M$ response by simultaneous stimulation of the ulnar nerve at the wrist and at the axilla in a normal subject. Compound action potential recorded with surface electrodes over abductor digiti minimi. The lower trace shows the $M$ response obtained by supramaximal stimulation of the ulnar nerve at the wrist and the middle trace that obtained by supramaximal stimulation of the ulnar nerve in the axilla. When both stimuli are delivered simultaneously (top trace), the antidromic volley generated at the wrist collides with the orthodromic volley originating at the axilla. The longer latency muscle compound action potential is therefore abolished.

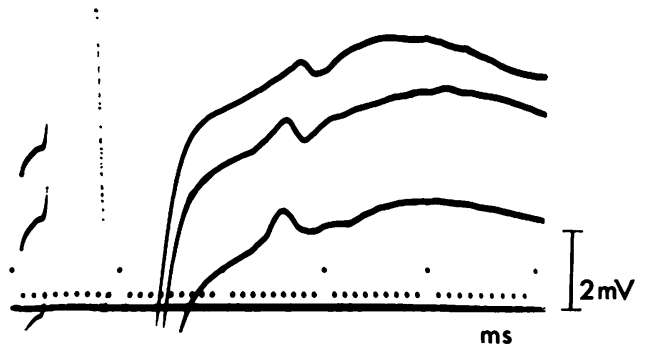

FIG. 2. Three $F$ waves obtained from stimulation of the ulnar nerve in the axilla in a normal subject. The collision technique permits these responses to be visualized. The initial deflection is the direct muscle response resulting from stimulation of the ulnar nerve at the wrist. The $F$ waves result from stimulation of the ulnar nerve in the axilla. The shortest latency to the onset of an $F$ wave is $23 \mathrm{~ms}$. The direct muscle response from the axillary stimulation is obliterated by collision with the antidromic volley generated at the wrist.

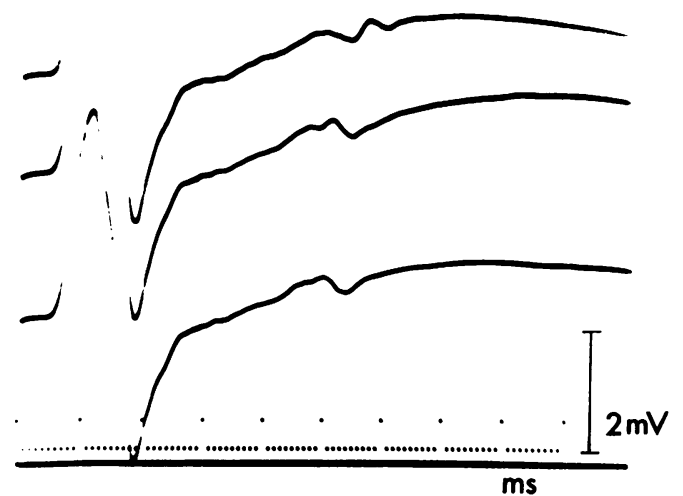

FIG. $3 F$ waves obtained from stimulation of the ulnar nerve in the axilla in a patient with the Guillain-Barré syndrome.

CONTROL SUBJECTS There was no significant difference between the mean proximal and the mean distal conduction velocities of the norma $\infty$ volunteers and the subjects referred for neuros physiological studies for conditions unlikely t affect conduction in the upper limbs. Thes 8 data were therefore pooled. In the control sube jects (Table 1) the mean calculated conductio velocity in the proximal segment, spinal cor

\section{T A B L E 1}

PROXIMAL AND DISTAL CONDUCTION VELOCITIES IN ULNAR NERVE FIBRES IN CONTROL SUBJECTS

\begin{tabular}{lllcc}
\hline Subject & $\begin{array}{c}\text { Age } \\
(\boldsymbol{y r})\end{array}$ & $\begin{array}{c}\text { Sex } \\
\text { Proximal conduction } \\
\text { velocity } \\
(\mathrm{m} / \mathrm{s})\end{array}$ & $\begin{array}{c}\text { Distal conduction } \\
\text { velocity } \\
(\mathrm{m} / \mathrm{s})\end{array}$ \\
\hline D.F. & 64 & M & 63.0 & 56.5 \\
A.E. & 46 & F & 67.0 & 50.0 \\
S.N. & 30 & F & 67.0 & 57.0 \\
R.M. & 31 & M & 65.0 & 51.0 \\
J.A. & 35 & F & 65.0 & 67.0 \\
K.H. & 48 & F & 62.5 & 63.0 \\
L.M. & 38 & F & 74.5 & 54.0 \\
S.C. & 46 & M & 61.0 & 61.0 \\
P.A. & 37 & M & 79.5 & 55.0 \\
D.K. & 32 & M & 60.0 & 59.0 \\
E.R. & 22 & F & 75.0 & 51.5 \\
J.M. & 31 & F & 58.0 & 49.5 \\
J.T. & 32 & F & 73.0 & 41.0 \\
M.V. & 26 & F & 64.0 & 64.0 \\
G.M. & 25 & M & 58.0 & 60.0 \\
G.P. & 35 & M & 78.5 & 57.0 \\
B.W. & 23 & F & 68.0 & 56.0 \\
\hline Mean & 35.3 & & 67.0 & 56.0 \\
S D & 10.7 & & 6.8 & 6.3 \\
\hline
\end{tabular}


T A B LE 2

PROXIMAL AND DISTAL CONDUCTION VELOCITIES IN ULNAR NERVE FIBRES IN PATIENTS WITH GUILLAIN-BARRÉ SYNDROME

\begin{tabular}{|c|c|c|c|c|c|c|c|}
\hline Patient & $\begin{array}{l}\text { Age } \\
(y r)\end{array}$ & Sex & $\begin{array}{l}\text { Severity at } \\
\text { examination }\end{array}$ & $\begin{array}{l}\text { CSF protein } \\
\text { at diagnosis } \\
(g / l)\end{array}$ & $\begin{array}{c}\text { Time after } \\
\text { onset } \\
\text { (months) }\end{array}$ & $\begin{array}{c}\text { Proximal conduction } \\
\text { velocity } \\
(\mathrm{m} / \mathrm{s})\end{array}$ & $\begin{array}{c}\text { Distal conduction } \\
\text { velocity } \\
(\mathrm{m} / \mathrm{s})\end{array}$ \\
\hline 1 M.C. & 55 & $\mathbf{M}$ & Severe & 0.78 & 0.25 & 2.3 & 23.5 \\
\hline 2 J.R. & 49 & $\mathbf{M}$ & Severe & 1.00 & 0.5 & 30.0 & 54.0 \\
\hline 3 L.C. & 94 & $\mathbf{M}$ & Severe & 1.31 & 1.0 & 34.0 & 36.5 \\
\hline 4 T.S. & 52 & $\mathbf{M}$ & Moderate & 1.09 & 4.0 & 35.0 & 26.0 \\
\hline 5 R.T. & 39 & $\mathbf{M}$ & Moderate & 1.42 & 4.5 & 37.0 & 42.0 \\
\hline 6 L.M. & 44 & $\mathbf{F}$ & Normal & 0.95 & 13.0 & 42.5 & 35.5 \\
\hline 7 B.R. & 19 & $\mathbf{M}$ & Mild & 1.13 & 24.0 & 59.0 & 48.5 \\
\hline 8 J.M. & 43 & $\mathbf{M}$ & Mild & 0.70 & 25.0 & 30.0 & 28.5 \\
\hline 9 E.R. & 17 & $\mathbf{M}$ & Normal & 0.61 & 36.0 & 72.0 & 50.0 \\
\hline 10 H.C. & 38 & $\mathbf{F}$ & Mild & 1.03 & 48.0 & 41.0 & 34.0 \\
\hline 11 J.H. & 22 & $\mathbf{M}$ & Moderate & 3.00 & 54.0 & 21.0 & 15.6 \\
\hline Mean & 42.9 & & & 1.184 & 19.1 & 36.7 & 35.8 \\
\hline S D & 21.4 & & & 0.649 & 19.8 & 18.2 & 10.6 \\
\hline
\end{tabular}

to axilla, of the ulnar nerve $(67 \mathrm{~m} / \mathrm{s})$ was significantly faster $(t=4.19 ; \mathrm{P}<0.001)$ than that of the distal segment, axilla to wrist $(56 \mathrm{~m} / \mathrm{s})$.

PATIENTS WITH THE GUILLAIN-BARRÉ SYNDROME The patients were examined at varying intervals after the onset of their disease, ranging from one week to four and a half years (Table 2). Both the distal conduction velocity (mean difference $=20.2 \mathrm{~m} / \mathrm{s} ; t=5.8 ; \mathrm{P}<0.001)$ and the proximal conduction velocity (mean difference $=30.2 \mathrm{~m} / \mathrm{s} ; t=6.2 ; \mathrm{P}<0.001$ ) were slower in the patients with GBS. There was a close correlation between the proximal and distal conduction velocities $(r=0.67 ; 0.05>\mathrm{P}>0.01)$ suggesting that the disease process, in general, affected both the proximal and the distal segments to roughly the same extent (Fig. 4). In two patients (cases 1 and 2), however, the conduction velocity in the proximal segment was disproportionally reduced and in one (case 2) the conduction velocity in the proximal segment was reduced, whereas conduction velocity in the distal segment, measured in the conventional manner, was within normal limits. Unlike the control population, there was no significant difference between the proximal and distal conduction velocities in the patient group.

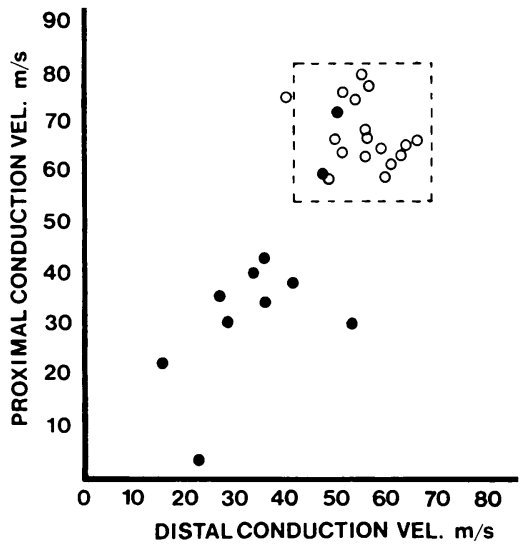

FIG. 4 Relationship between proximal and distal conduction velocities in the ulnar nerve in normal subjects $(O)$ and patients with the Guillain-Barré syndrome (O). The mean $\pm 2 S D$ for normal subjects is indicated by the dotted lines. Proximal conduction velocity is slightly faster than distal conduction velocity in normal subjects. In patients with the Guillain-Barré syndrome proximal and distal conduction appear, in general, to be equally affected but in two patients proximal conduction velocity is disproportionally reduced. In one patient proximal conduction velocity is reduced, although distal conduction velocity is within normal limits. 
The CSF protein, measured during the acute phase of the illness, was raised in all patients. There was no correlation between the CSF protein and either proximal or distal conduction velocity either in the group as a whole or in those in whom the studies were carried out within six months of the onset. There were more males in the patient population than in the control group but, although this may affect conduction velocity (LaFratta and Smith, 1964), it is considered unlikely to account for the present findings. There was no statistically significant difference between the mean ages of the two groups.

\section{DISCUSSION}

It is likely that the $\mathbf{F}$ wave obtained in relaxed normal man is attributable to recurrent activation of motoneurones by the antidromic volley in the motor nerve. It can be obtained in man or in the experimental animal when reflex activity has been abolished by deafferentation (Magladery and McDougal, 1950; Gassel and Wiesendanger, 1965; Thorne, 1965; McLeod and Wray, 1966; Mayer and Feldman, 1967) or myelotomy (Miglietta, 1973) and it can be recorded from the facial muscles, which are believed to be devoid of muscle afferent nerves (Sawnhey and Kayan, 1970; Trontelj and Trontelj, 1973). The ascending and descending volleys travel at the same velocity (Dawson and Merton, 1956; Mayer and Feldman, 1967; Miglietta, 1973; Trontelj, 1973), although this may not be the same as the conduction velocity of the fastest conducting motor fibres (Magladery and McDougal, 1950). A motor unit does not take part in the late response unless it has already appeared as a component of the direct muscle response (Thorne, 1965; Trontelj, 1973; Trontelj and Trontelj, 1973). Unlike a true reflex response, such as the $\mathrm{H}$ reflex, the $F$ wave is not abolished by supramaximal stimulation of the motor nerve. It is unaffected by post-tetanic potentiation and does not suffer prolonged inhibition after a conditioning stimulus (Thorne, 1965; Mayer and Feldman, 1967). A reflex response of similar latency, however, may be superimposed upon the $\mathbf{F}$ wave with proximal sites of stimulation (Fra and Bignolio, 1968) and when the excitability of the motoneurones is enhanced by voluntary contraction (Upton et al., 1971), prior tetanic stimulation (Hagbarth, 1962), or as a result of an upper motor neurone lesion (Thorne, 1965).

It therefore appears reasonable to assume that $\mathbf{F}$ waves obtained in a relaxed subject result predominantly from the antidromic activation of a small number of motoneurones.

The measurement of motor conduction velocity using the $F$ wave is, however, subject to two reservations.

1. Although the motor units involved in the $\mathrm{F}$ wave may be large (Feasby and Brown, 1974), their axons are not necessarily the fastest conducting motor axons of that nerve. It appears unlikely, however, that the $F$ wave results from the antidromic activation of motor nerve fibres of all sizes in a completely random manner since the standard deviation of the proximal estimate (in which conduction velocity is measured in the fibres carrying the $\mathrm{F}$. wave) is no greater than the standard devia- $\frac{}{1}$ i tion of the distal estimate (in which conduction $\frac{\overrightarrow{\mathrm{D}}}{\infty}$ velocity is measured in the fastest conducting fibres).

2. The estimate of the distance from the spinal cord to the proximal point of stimulation could be subject to a consistent error. This does not invalidate the use of the technique for comparative purposes provided that the measurement is made in the same way in a control group in each laboratory.

In the control subjects the calculated conduction velocity in the fibres of the ulnar nerve was faster proximally than distally. While this could be attributed to a consistent underestimate of the proximal distance, faster conduction in the proximal portions of peripheral nerves has been documented previously. This subject has been reviewed by Kaeser (1970).

In the majority of patients with GBS, conduction was reduced proportionally in the proximal and distal portions of the nerve, suggesting that the disease is, in general, a diffuse process. However, the difference between the proximal and distal conduction velocities noted in the control subjects was not apparent in the group with GBS. These findings could indicate that demyelination is more pronounced proximally, although the proximal segments were longer than the distal segments and would be 
more likely to show a reduction in overall conduction velocity as a result of a random process of segmental demyelination. In one patient proximal conduction velocity was reduced while distal conduction velocity, measured in the conventional manner, was normal. The technique may therefore be of value in establishing the diagnosis in some of those patients $(14-20 \%)$ in whom distal conduction velocities are normal.

Kimura and Butzer (1975) made serial estimations of proximal and distal conduction velocity in the median and ulnar nerves of nine patients with GBS. They found that slowing of conduction was initially most common at sites of possible nerve compression and in the central segment between spinal cord and axilla. In four patients only proximal conduction was slowed. They concluded that the central segment may be predominantly involved in some patients with GBS.

Although GBS is considered to be predominantly a demyelinating disease (Asbury et al., 1969; Wisniewski et al., 1969; Carpenter, 1972), axonal damage occurs (Finean and Woolf, 1962; Asbury et al., 1969; Qppenheimer and Spalding, 1973; Arnason, 1975). Electrophysiological evidence of axonal disruption is found in $20-50 \%$ of patients with GBS (Pleasure et al., 1968; De Jesus, 1974; Eisen and Humphreys, 1974). It has been established that the prognosis in GBS depends on the extent of the denervation rather than on the degree of slowing of motor conduction velocity (Isch et al., 1967; Oppenheimer and Spalding, 1973; Eisen and Humphreys, 1974; but see McQuillan, 1971).

The measurement of conduction velocity in the proximal portions of a motor nerve may therefore have additional value. Normal conduction in both the proximal and distal segments in the presence of severe weakness would raise the possibility of conduction block or the presence of a predominantly axonal lesion with the associated poor prognosis.

It is concluded that the estimation of conduction velocity in the proximal portions of a motor nerve using the method devised by Kimura (1974) may be valuable in the more complete assessment of patients with GBS.

\section{REFERENCES}

Arnason, B. G. W. (1975). Inflammatory polyradiculoneuropathies. In Peripheral Neuropathy, vol. 2, pp. 1100-1148. Edited by P. J. Dyck, P. K. Thomas, and E. H. Lambert. Saunders: Philadelphia.

Asbury, A. K., Arnason, B. G., and Adams, R. D. (1969). The inflammatory lesion in idiopathic polyneuritis. Medicine (Balt.), 48, 173-215.

Bigot, P., and Goulon, M. (1970). Evolution of electrological data in polyradiculitis. Electroencephalography and Clinical Neurophysiology, 29, 534.

Carpenter, S. (1972). An ultrastructural study of an acute fatal case of the Guillain-Barré syndrome. Journal of the Neurological Sciences, 15, 125-140.

Cerra, D., and Johnson, E. W. (1961). Motor nerve conduction velocity in 'idiopathic' polyneuritis. Archives of Physical Medicine and Rehabilitation, 42, 159-163.

Dawson, G. D., and Merton, P. A. (1956). 'Recurrent' discharges from motoneurones, pp. 221-222. Twentieth International Congress of Physiology. Brussels: Abstract of Communications.

De Jesus, P. V. (1974). Landry-Guillain-Barré-Strohl syndrome neuronal disorder and clinico-electrophysiological correlation. Electromyography and Clinical Neurophysiology, 14, 115-132.

Eisen, A., and Humphreys, P. (1974). The GuillainBarré syndrome. A clinical and electrodiagnostic study of 25 cases. Archives of Neurology (Chic.), 30, 438-443.

Feasby, T. E., and Brown, W. F. (1974). Variation of motor unit size in the human extensor digitorum brevis and thenar muscles. Journal of Neurology, Neurosurgery, and Psychiatry, 37, 916-926.

Finean, J. B., and Woolf, A. L. (1962). An electron microscope study of degenerative changes in human cutaneous nerve. Journal of Neuropathology and Experimental Neurology, 21, 105-115.

Fra, L., and Bignolio, F. (1968). $\mathrm{F}$ and $\mathrm{H}$ responses elicited from muscles of the lower limb in normal subjects. Journal of the Neurological Sciences, 7, 251-261.

Gassel, M. M., and Wiesendanger, M. (1965). Recurrent and reflex discharges in plantar muscles of the cat. Acta Physiologica Scandinavica, 65, 138-142.

Hagbarth, K-E. (1962). Post-tetanic potentiation of myotatic reflexes in man. Journal of Neurology, Neurosurgery, and Psychiatry, 25, 1-10.

Humphreys, J. G. (1964). Motor nerve conduction studies in the Landry-Guillain-Barre syndrome (acute ascending polyneuropathy). Electroencephalography and Clinical Neurophysiology, 17, 96.

Isch, F., Isch-Treussard, C., and Jesel, M. (1967). Valeur diagnostique et pronostique des données électromyographiques dans les polyradiculonévrites. Revue Neurologique, 117, 21-34. 
Kaeser, H. E. (1970). Nerve conduction velocity measurements. In Handbook of Clinical Neurology, vol. 7, pp. 116-196. Edited by P. J. Vinken and G. W. Bruyn. Elsevier: New York.

Kimura, J. (1974). F-wave velocity in the central segment of the median and ulnar nerves. A study in normals and in Charcot-Marie-Tooth disease. Neurology (Minneap.) 24, 539-546.

Kimura, J., and Butzer, J. F. (1975). F-wave conduction velocity in Guillain-Barré syndrome. Assessment of nerve segment between axilla and spinal cord. Archives of Neurology (Chic.), 32, 524-529.

LaFratta, C. W., and Smith, O. H. (1964). A study of the relationship of motor nerve conduction velocity in the adult to age, sex and handedness. Archives of Physical Medicine and Rehabilitation, 45, 407-412.

Lambert, E. H., and Mulder, D. W. (1964). Nerve conduction in the Guillain-Barré syndrome. Electroencephalography and Clinical Neurophysiology, 17, 86.

Magladery, J. W., and McDougal, D. B. (1950). Electrophysiological studies of nerve and reflex activity in normal man. 1 . Identification of certain reflexes in the electromyogram and the conduction velocity of peripheral nerve fibres. Bulletin of the Johns Hopkins Hospital, 86, 265-290.

Mayer, R. F., and Feldman, R. G. (1967). Observations on the nature of the $F$ wave in man. Neuro$\operatorname{logy}$ (Minneap.), 17, 147-156.

McLeod, J. G., and Wray, S. H. (1966). An experimental study of the $F$ wave in the baboon. Journal of Neurology, Neurosurgery, and Psychiatry, 29, 196-200.

McQuillen, M. P. (1971). Idiopathic polyneuritis: serial studies of nerve and immune functions. Journal of Neurology, Neurosurgery, and Psychiatry, 34, 607-615.

Miglietta, O. E. (1973). The F response after transverse myelotomy. In: New Developments in Electromyography and Clinical Neurophysiology, vol. 3, pp. 323-327. Edited by J. E. Desmedt. Karger: Basel.
Oppenheimer, D. R., and Spalding, J. M. K. (1973). Late residua of acute idiopathic polyneuritis. Journal of Neurology, Neurosurgery, and Psychiatry, 36, 978-988.

Peterman, A. F., Daly, D. D., Dion, F. R., and Haddow, M. K. (1959). Infectious neuronitis (Guillain-Barré syndrome) in children. Neurology (Minneap.), 9, 533-539.

Pleasure, D. E., Lovelace, R. E., and Duvoisin, R. C. (1968). The prognosis of acute polyradiculoneuritis. Neurology (Minneap.), 18, 1143-1148.

Rasminsky, M., and Sears, T. A. (1973). Saltatory conduction in demyelinated nerve fibres. In New Developments in Electromyography and Clinical Neurophysiology, vol. 2, pp. 158-165. Edited by J. E. Desmedt. Karger: Basel.

Sawnhey, B. B., and Kayan, A. (1970). A study of the $F$ wave from the facial muscles. Electromyography, 10, 287-295.

Thorne, J. (1965). Central responses to electrical activation of the peripheral nerves supplying the intrinsic hand muscle. Journal of Neurology, Neurosurgery, and Psychiatry, 28, 482-495.

Trontelj, J. V. (1973). A study of the F response by single fibre electromyography. In New Developments in Electromyography and Clinical Neuro physiology, vol. 3, pp. 318-322. Edited by J. E. Desmedt. Karger: Basel.

Trontelj, J. V., and Trontelj, M. (1973). F-responsesô. of human facial muscles. A single motoneurone? study. Journal of the Neurological Sciences, 20, 211-222.

Upton, A. R. M., McComas, A. J., and Sica, R. E. P. (1971). Potentiation of 'late' responses evoked in muscles during effort. Journal of Neurology, Neurosurgery, and Psychiatry, 34, 699-711.

Wiśniewski, H., Terry, R. D., Whitaker, J. N., Cook, S. D., and Dowling, P. C. (1969). Landry-GuillainBarré syndrome. A primary demyelinating disease. Archives of Neurology (Chic.), 21, 269-276. 